BMJ

Open

Gastroenterology

\title{
Novelty in the gut: a systematic review and meta-analysis of the gastrointestinal manifestations of COVID-19
}

\author{
Vishnu Charan Suresh Kumar (1) , ${ }^{1}$ Samiran Mukherjee, ${ }^{1}$ Prateek Suresh Harne, ${ }^{1}$ \\ Abinash Subedi, ${ }^{1}$ Muthu Kuzhali Ganapathy, ${ }^{2}$ Venkata Suresh Patthipati, ${ }^{3}$ \\ Bishnu Sapkota ${ }^{4,5}$
}

To cite: Suresh Kumar VC, Mukherjee S, Harne PS, et al. Novelty in the gut: a systematic review and meta-analysis of the gastrointestinal manifestations of COVID-19. BMJ Open Gastro 2020;7:e000417. doi:10.1136/ bmjgast-2020-000417

Received 8 April 2020 Revised 4 May 2020 Accepted 6 May 2020
Check for updates

(C) Author(s) (or their employer(s)) 2020. Re-use permitted under CC BY-NC. No commercial re-use. See rights and permissions. Published by BMJ.

${ }^{1}$ Department of Internal Medicine, SUNY Upstate Medical University, Syracuse, New York, USA

${ }^{2}$ Department of General Medicine, Sri Ramaswamy Memorial Group of Educational Institutions, Chennai, Tamil Nadu, India

${ }^{3}$ Department of Internal Medicine, Trumbull Regional Medical Center, Warren, Ohio, USA

${ }^{4}$ Division of Gastroenterology, Syracuse VA Medical Center, Syracuse, New York, USA ${ }^{5}$ Division of Gastroenterology, SUNY Upstate Medical University, Syracuse, New York, USA

Correspondence to Dr Vishnu Charan Suresh Kumar;

drvishnucharan@gmail.com

\section{ABSTRACT}

Background The COVID-19 epidemic has affected over 2.6 million people across 210 countries. Recent studies have shown that patients with COVID-19 experience relevant gastrointestinal (Gl) symptoms. We aimed to perform a systematic review and meta-analysis on the GI symptoms of COVID-19.

Methods A literature search was conducted via electronic databases, including PubMed, Embase, Scopus, and Google Scholar, from inception until 20 March 2020. Data were extracted from relevant studies. A systematic review of Gl symptoms and a meta-analysis comparing symptoms in severe and non-severe patients was performed using RevMan V.5.3.

Results Pooled data from 2477 patients with a reverse transcription-PCR-positive COVID-19 infection across 17 studies were analysed. Our study revealed that diarrhoea ( $7.8 \%)$ followed by nausea and/or vomiting (5.5\%) were the most common Gl symptoms. We performed a metaanalysis comparing the odds of having Gl symptoms in severe versus non-severe COVID-19-positive patients. 4 studies for nausea and/or vomiting, 5 studies for diarrhoea and 3 studies for abdominal pain were used for the analyses. There was no significant difference in the incidence of diarrhoea ( $0 \mathrm{R}=1.32,95 \% \mathrm{Cl} 0.8$ to 2.18 , $Z=1.07, p=0.28, I^{2}=17 \%$ ) or nausea and/or vomiting ( $\mathrm{OR}=0.96,95 \% \mathrm{Cl} 0.42$ to $2.19, \mathrm{Z}=0.10, \mathrm{p}=0.92, \mathrm{I}^{2}=55 \%$ ) between either group. However, there was seven times higher odds of having abdominal pain in patients with severe illness when compared with non-severe patients (OR=7.17, $95 \% \mathrm{Cl} 1.95$ to $26.34, \mathrm{Z}=2.97, \mathrm{p}=0.003$, $\mathrm{I}^{2}=0 \%$ ).

Conclusion Our study has reiterated that Gl symptoms are an important clinical feature of COVID-19. Patients with severe disease are more likely to have abdominal pain as compared with patients with non-severe disease.

\section{INTRODUCTION}

At the time of writing this paper, over 2.6 million people across 210 countries have been infected with the severe acute respiratory syndrome coronavirus 2 (SARS-CoV-2) virus. ${ }^{1}$ The impact of the virus has been devastating on a global scale. National healthcare

\section{Summary box}

What is already known about this subject?

- Fever, cough, and shortness of breath have been described as the most common symptoms of COVID-19.

- A significant number of patients may present with gastrointestinal (Gl) symptoms.

What are the new findings?

- Comparison of Gl symptoms between patients with severe disease and patients with non-severe disease.

- Abdominal pain is seen more in patients with severe disease and could be an indicator for disease severity.

How might it impact on clinical practice in the foreseeable future?

- Gives better understanding and insight into the complete spectrum of GI manifestations of COVID-19.

- Helps develop a prognostic tool based on clinical symptoms.

systems have been overwhelmed, resulting in nationwide lockdowns, international travel has come to a complete standstill, and healthcare workers world over have been faced with shortages of personal protective equipment. Since its initial outbreak in Hubei in December 2019, the number of COVID-19positive patients has risen at an exponential rate. ${ }^{2-4}$ As of 24 April 2020, the USA alone has witnessed over 865000 cases which is a sharp increase from its census of 10000 merely 4 weeks prior. ${ }^{5}$ The transmissibility of the virus, coupled with a large number of asymptomatic cases, has been held as the culprit behind a rapid rise in incidences, with every infected person being able to further infect another 2.2 people. $^{6}$

Numerous studies have attempted to try and describe the virus from both an epidemiological and clinical perspective. ${ }^{7-10}$ Although the 


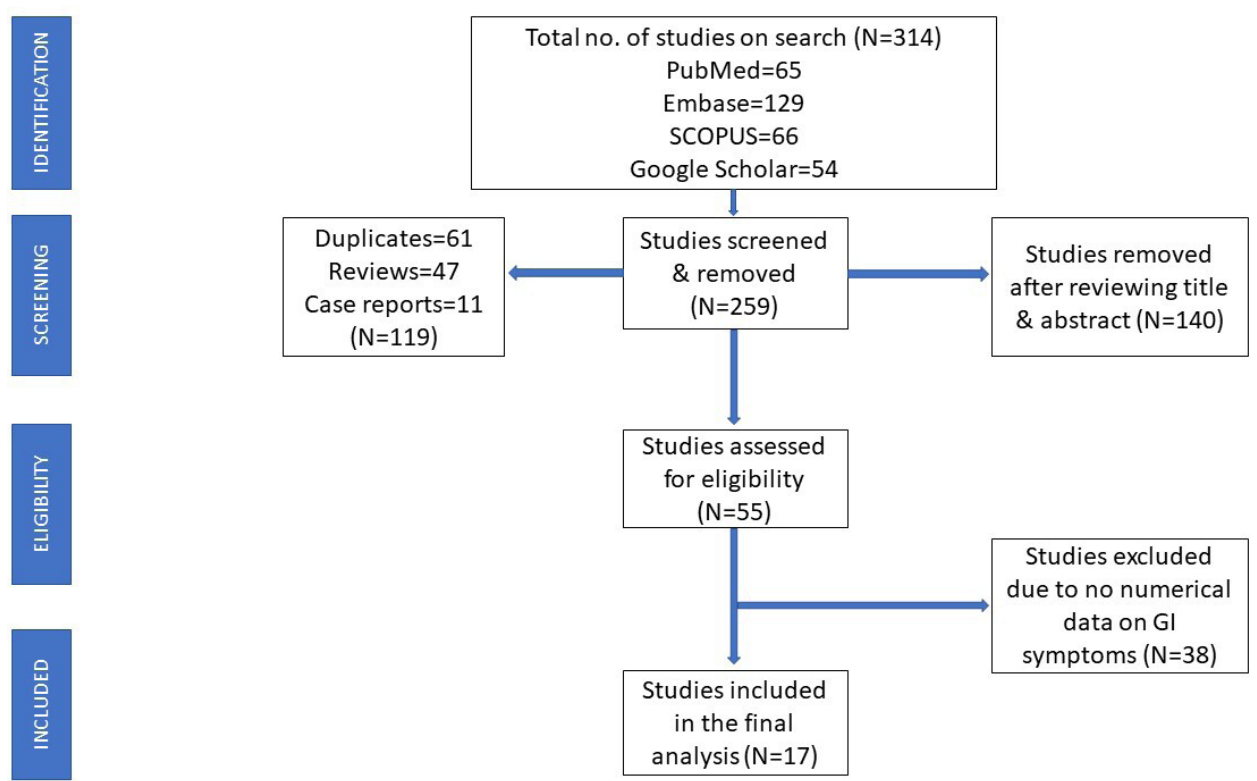

Figure 1 Study flow diagram. Gl, gastrointestinal.

most commonly described symptoms in patients appear to be fever $(75 \%-98 \%)$ and cough $(39 \%-81 \%),{ }^{7811-13}$ it appears that a significant number of patients may present with gastrointestinal (GI) symptoms as well. ${ }^{1415}$

Among the GI symptoms that have been described, diarrhoea appears to be the most common $(3 \%-34 \%) .{ }^{1214-16}$ Symptoms less reported included nausea $(1 \%-17 \%),{ }^{7-9}$ vomiting $(1 \%-4 \%),{ }^{7} 14$ abdominal pain $(2 \%-5 \%)^{8} 914$ and GI bleeding $(0 \%-13 \%) .{ }^{10} 16$ This is of paramount importance as it implies that a patient with COVID-19 may, in fact, masquerade as a presumed gastroenteritis until the respiratory symptoms predominate.

Work on the possible pathophysiology behind the GI symptoms remains ongoing. Studies have hypothesised that the ACE2 receptor, which is used by the virus to infect cells, is also expressed in the mucosa of the GI tract and may play a role in its GI manifestation. ${ }^{16} 17$ Viral colonisation of the immune-rich areas of the gut contributes to a systemic inflammatory response. ${ }^{14}$ Further, there is growing evidence that the virus present in stool samples can continue to persist in the stool long after the respiratory colonisation resolves to hypothesise a faecal-oral route of transmission. ${ }^{1416}$

As the evolution of the pandemic continues to be dynamic with new advances being reported on an almost hourly basis, we aimed to perform systematic review of GI symptoms of COVID-19 from its inception until 20 March 2020, and meta-analysis comparing GI symptoms in severe versus non-severe disease. To our knowledge, this is the first study to do so.

\section{METHODS}

\section{Search strategy}

A comprehensive search of several databases, including PubMed, Embase, Scopus and Google Scholar databases from inception to 20 March 2020, was conducted. An expert medical librarian using inputs from the authors helped conduct the literature search. Keywords used in the search included a combination of 'COVID-19 or coronavirus or SARS-COV' and 'Gastrointestinal symptoms', and 'Clinical features'. We used the Meta-analysis of Observational Studies in Epidemiology (MOOSE) guidelines and a predefined protocol to identify studies reporting GI symptoms of COVID-19. We restricted our search to studies that have been published or accepted in peer-reviewed journals. We restricted our search to studies published in English. Based on preset inclusion and exclusion criteria, three authors (VCSK, SM and AS) independently reviewed the studies and excluded studies that did not address our topic. The selected articles were reviewed to determine whether they contained relevant data. The bibliographic sections were manually searched for similar studies. Any discrepancy in included studies was resolved by a coauthor $(\mathrm{PH})$.

\section{Study selection}

We included cohort studies and case series which met our inclusion criteria, which included: (1) reverse transcription-PCR-confirmed COVID-19 cases; (2) age $>18$ years; (3) description of clinical symptoms; and (4) data on the number of patients with GI symptoms. Studies included satisfied all aspects of the inclusion criteria. We only included studies that were published in English. Our exclusion criteria included: (1) no data on GI symptoms; (2) age <18 years; (3) patients with other SARS-like illnesses; and (4) case reports. Studies that had any one of these were excluded from our final study.

\section{Data extraction and quality assessment}

A data extraction sheet was created, and the study characteristics, data on intended outcomes, and patient characteristics were collected. Three of the authors (VCSK, SM, and AS) independently extracted data. Extracted 


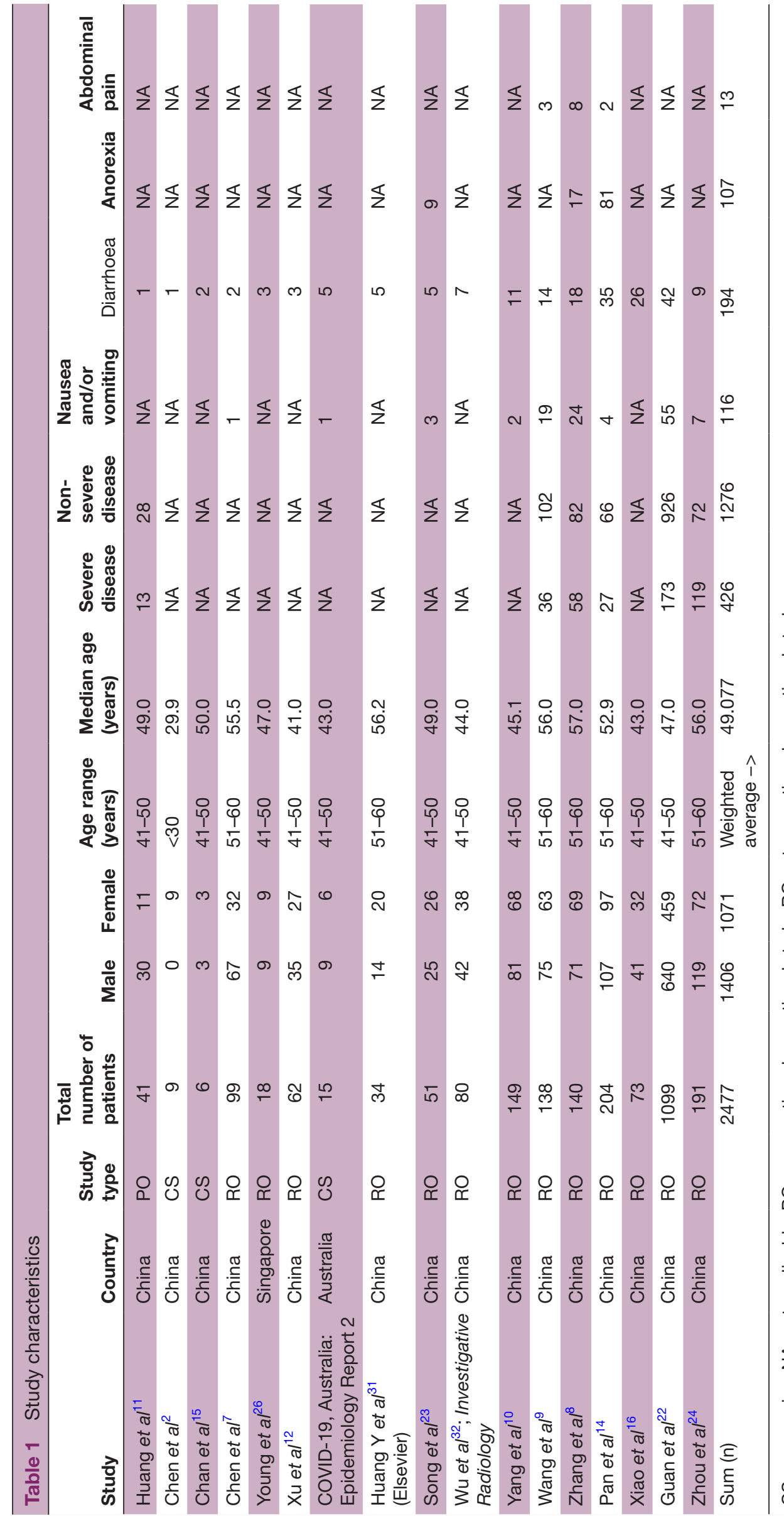

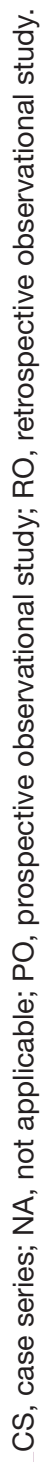




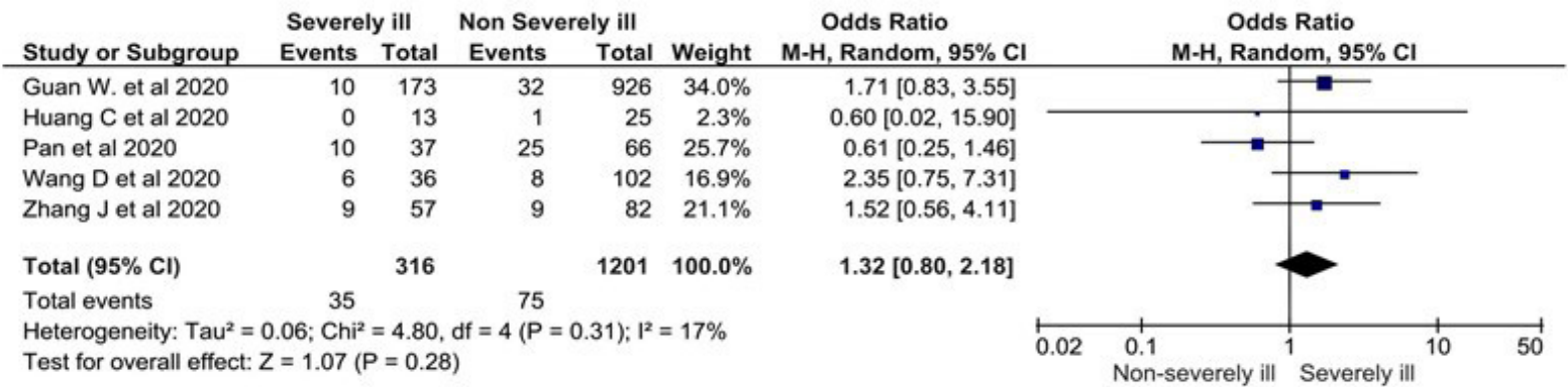

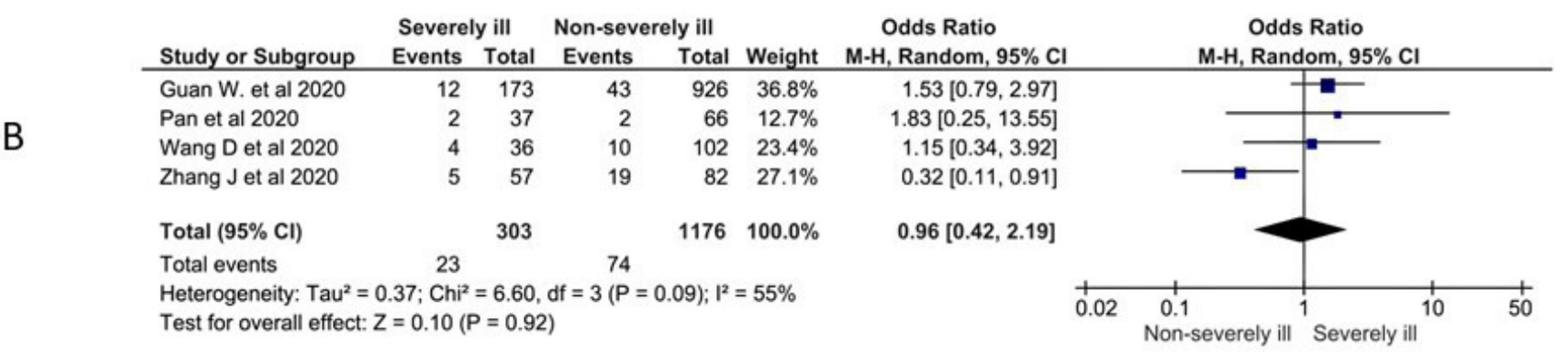

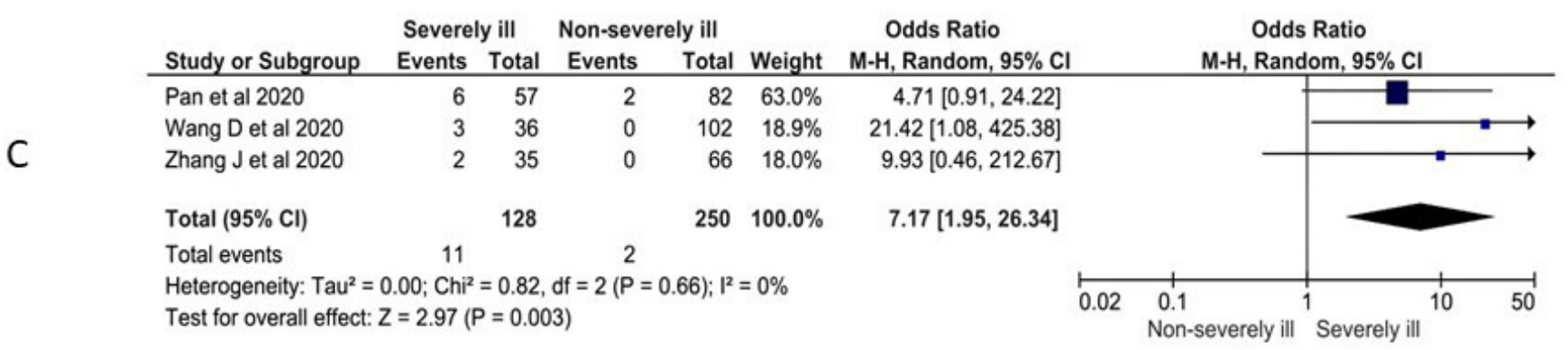

Figure 2 Forest plots comparing patients with severe versus non-severe disease based on symptoms. (A) Diarrhoea, (B) nausea and/or vomiting, (C) abdominal pain.

data were reviewed by two authors (PH and MKG) for potential discrepancies, which, if present, were resolved.

The quality of included studies was determined objectively using a scale based on the Newcastle-Ottawa Scale for meta-analysis. ${ }^{18}$ The scale consisted of eight questions, each of which was awarded one star, amounting to a maximum possible eight stars per study. We scored the comparability questions based on the outcomes that our study intended to find and not based on comparison outcomes for individual outcomes from the original studies. We considered a total score of $>/=7,3-6$, and $<2$ represented high, fair, and poor-quality studies, respectively. Two authors (SM and VCSK) independently assessed the quality of the studies. The senior author (BS) reviewed the final quality assessment table and resolved discrepancies if there were any.

\section{Outcomes}

The primary outcome of the systematic review was to describe the occurrence of GI symptoms in patients tested positive for COVID-19 and to establish the most common of the symptoms. The secondary outcome was to compare GI symptoms in patients with severe versus non-severe COVID-19 disease. The definition of 'severe' was based on either the National Chinese Health Commission (seventh) edition definition ${ }^{19}$ or the American Thoracic Society ${ }^{20}$ definition as these had been the criteria used within the analysed studies.

\section{Statistical analysis}

Our analysis includes cumulative descriptive statistics expressed as counts (n) and percentages (\%) with a comparative analysis for the selected studies and a subgroup analysis for each symptom using TIBCO Spotfire analytics and spreadsheet tools. For comparing GI symptoms in severe versus non-severe cases, a metaanalysis was performed using the RevMan V.5.3 generating forest plots and funnel plots. Publication bias was assessed based on symmetry of the funnel plots. Due to a small sample set ( $<10$ studies), statistical testing using Egger's or Begg's test was deferred. We computed the OR as our effect estimate using the Mantel-Haenszel method 
Table 2 Abdominal pain in patients with severe versus non-severe disease

\begin{tabular}{llllllll}
\hline & Severe & & & Non-severe & \\
\cline { 2 - 3 } Study & $\begin{array}{l}\text { Abdominal } \\
\text { pain }\end{array}$ & $\begin{array}{l}\text { No } \\
\text { pain }\end{array}$ & & $\begin{array}{l}\text { Abdominal } \\
\text { pain }\end{array}$ & $\begin{array}{l}\text { No } \\
\text { pain }\end{array}$ & $\begin{array}{l}\text { Total } \\
\mathbf{n}\end{array}$ \\
\hline Zhang et $a l^{8}$ & 6 & 51 & 2 & 80 & 139 \\
Wang et $a l^{9}$ & 3 & 33 & 0 & 102 & 138 \\
Pan et al $^{14}$ & 2 & 35 & 0 & 66 & 103 \\
\hline Total, $\mathrm{n}$ & 11 & 119 & 2 & 248 & 380 \\
\hline
\end{tabular}

with random effects with a study CI of $95 \%$. We have used MOOSE guidelines and checklist for reporting our metaanalysis for this being an observational epidemiological review.

\section{RESULTS}

A total of 314 studies were identified using our search strategy, of which 119 studies were removed after initial screening for duplicates, review articles, and case reports. A further 140 studies were removed after reviewing the title and abstract. A total of 55 articles were assessed for eligibility, and after excluding 38 studies which did not contain numerical data of GI symptoms, 17 studies were included in the final analysis (figure 1). The study characteristics are described in table 1 . All 17 studies described the gender and mean age of the patients. The number of patients with diarrhoea was described in all the studies. However, only six studies had data on patients with nausea and/or vomiting, and only three studies had data on patients with anorexia and abdominal pain.

There is a considerable overlap of symptoms with at least nine out of the 17 studies reporting two or more symptoms. With a minimal estimate of 323 patients having at least one GI symptom of the 2477 patients, one in every eight (13\%) had at least one GI symptom. In our subgroup analysis, 115 (5.6\%) had nausea and/or vomiting of 2071 patients included from eight studies. One hundred and ninety-four patients $(7.8 \%)$ reported diarrhoea of 2477 from 17 studies. One hundred and seven $(27.1 \%)$ patients reported anorexia of the 395 included from three studies. Thirteen $(2.7 \%)$ were noted to have abdominal pain of the 482 patients from three studies.

We performed meta-analyses comparing the odds of having GI symptoms in severe versus non-severe patients. Four studies for nausea and/vomiting, five studies for diarrhoea, and three studies for abdominal pain were used for the analyses. There was no significant difference in the incidence of diarrhoea $(\mathrm{OR}=1.32,95 \%$ CI 0.8 to 2.18, $\mathrm{Z}=1.07, \mathrm{p}=0.28, \mathrm{I}^{2}=17 \%$ ) as indicated in figure $2 \mathrm{~A}$ or nausea and/vomiting ( $\mathrm{OR}=0.96,95 \%$ CI 0.42 to 2.19 , $\mathrm{Z}=0.10, \mathrm{p}=0.92, \mathrm{I}^{2}=55 \%$ ) as mentioned in figure $2 \mathrm{~B}$ in severe versus non-severe patients. However, when evaluating abdominal pain, it was revealed that severely affected patients were over 7.17 times likely to possess abdominal pain when compared with non-severe patients $\left(\mathrm{OR}=7.17,95 \%\right.$ CI 1.95 to $\left.26.34, \mathrm{Z}=2.97, \mathrm{p}=0.003, \mathrm{I}^{2}=0 \%\right)$, as displayed in figure 2C. Abdominal pain, diarrhoea and nausea and/or vomiting in patients with severe versus non-severe disease are shown in tables $2-4$, respectively.

\section{Study quality and bias assessment}

A total of five studies were included in the meta-analysis. Four of these had a Newcastle-Ottawa Scale score of 7 or greater, signifying high quality. The remaining study was evaluated to be of fair quality with a score of 5. Overall, studies included in the meta-analysis were of moderate to high quality (table 5 ).

There seemed to be no significant heterogeneity for the studies included in the analysis of diarrhoea $\left(\mathrm{I}^{2}=17 \%\right)$ and abdominal pain $\left(\mathrm{I}^{2}=0 \%\right)$, but the studies included in the analysis of nausea and/or vomiting exhibited moderate heterogeneity $\left(\mathrm{I}^{2}=55 \%\right)$.

There seemed to be evidence for publication bias based on the funnel plots (figure 3).

\section{DISCUSSION}

From its inception in December 2019 until the date of this manuscript, the COVID-19 pandemic has rapidly spread across the world with over 2.6 million cases being reported across different continents. ${ }^{1}$ Although much is already known of its commonly presenting symptoms such as fever $(75 \%-98 \%)$ and cough $(39 \%-81 \%),{ }^{7811-13}$ our review seeks to present an interesting association of GI symptoms with COVID-19 as depicted in figure 4.

In their study of 204 patients, Pan et al reported GI symptoms as a part of the initial presentation in about $50 \%$ of the patients while Zhang et al reported GI symptoms in $39.6 \%$ of their sample of 140 patients. ${ }^{814}$ In the former study, they had additionally reported six cases that solely presented with GI symptoms devoid of respiratory complaints. In line with these studies, our analysis revealed that a minimal estimate of 323 patients had at least one GI symptom of the 2477 patients. One in every eight patients $(13 \%)$ had at least one GI symptom.

We attempted to break our primary and secondary outcomes down as per the commonly reported GI symptoms in COVID-19-positive patients.

\section{Abdominal pain}

Three studies, including 380 patients, were analysed in our meta-analysis. ${ }^{814}$ Our findings suggested that patients with severe COVID-19 infection were almost seven times more likely to have abdominal pain as compared with their non-severe disease counterparts. Based on these results, abdominal pain could potentially serve as an indicator of severity in patients with COVID-19 infection to aid from triaging to deciding the aggressiveness of management.

In the systematic review, this was a sparsely reported complaint. A combined total of 13 out of 482 patients (2.7\%) reported abdominal pain. Pan et al reported abdominal pain in $2(1.9 \%)$ of the 103 patients, Zhang 
Table 3 Diarrhoea in patients with severe versus non-severe disease

\begin{tabular}{|c|c|c|c|c|c|}
\hline \multirow[b]{2}{*}{ Study } & \multicolumn{2}{|l|}{ Severe } & \multicolumn{2}{|c|}{ Non-severe } & \multirow{2}{*}{$\begin{array}{l}\text { Tota } \\
\mathbf{n}\end{array}$} \\
\hline & Diarrhoea & No diarrhoea & Diarrhoea & No diarrhoea & \\
\hline Huang et $a l^{11}$ & 0 & 13 & 1 & 24 & 38 \\
\hline Zhang et $a l^{8}$ & 9 & 48 & 9 & 73 & 139 \\
\hline Wang et $a l^{9}$ & 6 & 30 & 8 & 94 & 138 \\
\hline Pan et $a l^{14}$ & 10 & 27 & 25 & 41 & 103 \\
\hline Guan et $a l^{22}$ & 10 & 163 & 32 & 894 & 1099 \\
\hline Total, $\mathrm{n}$ & 35 & 281 & 75 & 1126 & 1517 \\
\hline
\end{tabular}

et al in $8(5.8 \%)$ patients, and Wang et al in $3(2.2 \%)$ patients. ${ }^{8914}$

\section{Diarrhoea}

In our meta-analysis, five studies met the inclusion criteria to measure the incidence of diarrhoea in patients with non-severe and severe COVID-19 infection. In our analysis of 1517 patients, we found that patients were more likely to have diarrhoea in the severe COVID-19 group when compared with its non-severe disease counterpart. This result was however not statistically significant, suggesting the need for more studies on the same to establish a true association.

Diarrhoea appeared to be the most common GI complaint in our review on patients with COVID-19, with its incidence ranging from $3 \%$ to $34 \%$. One hundred and ninety-four out of 2477 patients $(7.8 \%)$ reported diarrhoea from all 19 studies combined. Pan et al and Xiao et al recorded it to be present in $34 \%$ and $35 \%$ out of the study samples of 105 and 73 patients, respectively. ${ }^{14} 16$ These studies may suggest that COVID-19 can masquerade as viral gastroenteritis leading to possible delayed and missed diagnosis.

In their case series of five patients who travelled from Wuhan, Chan et al found two patients to have had diarrhoea with fever as the sole presentation, prior to the onset of respiratory complaints. Diarrhoea can thus serve as an early manifestation of certain COVID-19 infections which may be implemented as a sign of early quarantine. ${ }^{15}$

It is also imperative that secondary causes of diarrhoea be ruled out, such as medications in patients with COVID-19 like hydroxychloroquine, lopinavir/ritonavir, which may serve as confounders. Hu et al found two out

\begin{tabular}{|c|c|c|c|c|c|}
\hline \multirow[b]{2}{*}{ Study } & \multicolumn{2}{|l|}{ Severe } & \multicolumn{2}{|c|}{ Non-severe } & \multirow[b]{2}{*}{$\begin{array}{l}\text { Total } \\
\text { n }\end{array}$} \\
\hline & Nausea & $\begin{array}{l}\text { No } \\
\text { nausea }\end{array}$ & Nausea & $\begin{array}{l}\text { No } \\
\text { nausea }\end{array}$ & \\
\hline Zhang et $a l^{8}$ & 5 & 52 & 19 & 63 & 139 \\
\hline Wang et $a l^{9}$ & 4 & 32 & 10 & 92 & 138 \\
\hline Pan et $\mathrm{al}^{14}$ & 2 & 35 & 2 & 64 & 103 \\
\hline Guan et $a l^{22}$ & 12 & 161 & 43 & 883 & 1099 \\
\hline Total, $\mathrm{n}$ & 23 & 280 & 74 & 1102 & 1479 \\
\hline
\end{tabular}

of their 24 'asymptomatic' patients developing diarrhoea in the setting of being recently started on lopinavir/ ritonavir and darunavir/cobicistat. ${ }^{21}$

\section{Nausea and/or vomiting}

In our meta-analysis, four studies were included in the analysis of 1497 patients focusing on nausea and/or vomiting as a symptom. ${ }^{891422}$ It was seen that patients with severe disease were more likely to report nausea than their non-severe disease counterparts; however, this finding was not statistically significant.

In our subgroup analysis, 115 (5.6\%) had nausea and/ or vomiting of the 2071 patients included from eight studies. The incidence ranged from $1 \%$ to $17 \%$ in all the included studies. These symptoms, along with a lack of appetite (107/395 (27.1\%) from three studies), seem to be a non-specific finding. However, given the right clinical setting, this may expedite COVID-19 diagnoses.

\section{Pathophysiology and possibility of feco-oral spread}

The virus is a positive-sense non-segmented singlestranded beta coronavirus. ${ }^{22}{ }^{23}$ The proposed mechanism of entry for the virus lies in its ability to attach to the ACE2, an extracellular membrane receptor expressed on epithelial cells. ${ }^{2425}$ A study conducted by Xiao et al revealed that the viral nucleocapsid protein was heavily expressed in the areas of the GI tract that possessed strong ACE2 expression such as the stomach, duodenum, and rectum and was noticeably lower in areas devoid of the receptor such as the oesophagus. This also coincides with the degree of expression of the ACE2 receptor in the aforementioned segments of the GI tract. ${ }^{16}{ }^{17}$ The viral colonisation of the gut via the gut expressed ACE2 receptors will result in continued viral shedding in the stool in the form of diarrhoea, long after resolution of the initial respiratory infection. ${ }^{16}$ Recent data also suggest that viral detection in the stool occurs independent of the presence of diarrhoea and can be as common as $50 \%$ of patients. ${ }^{26}$

The clinical implications of this are profound, as it brings to light a possible faecal mode of transmission, as has been postulated by recent studies. ${ }^{16}$ One may infer that the presence of GI symptoms, in addition to the commonly reported symptoms of cough and fever, should be monitored as a sign of an actively infectious state. 


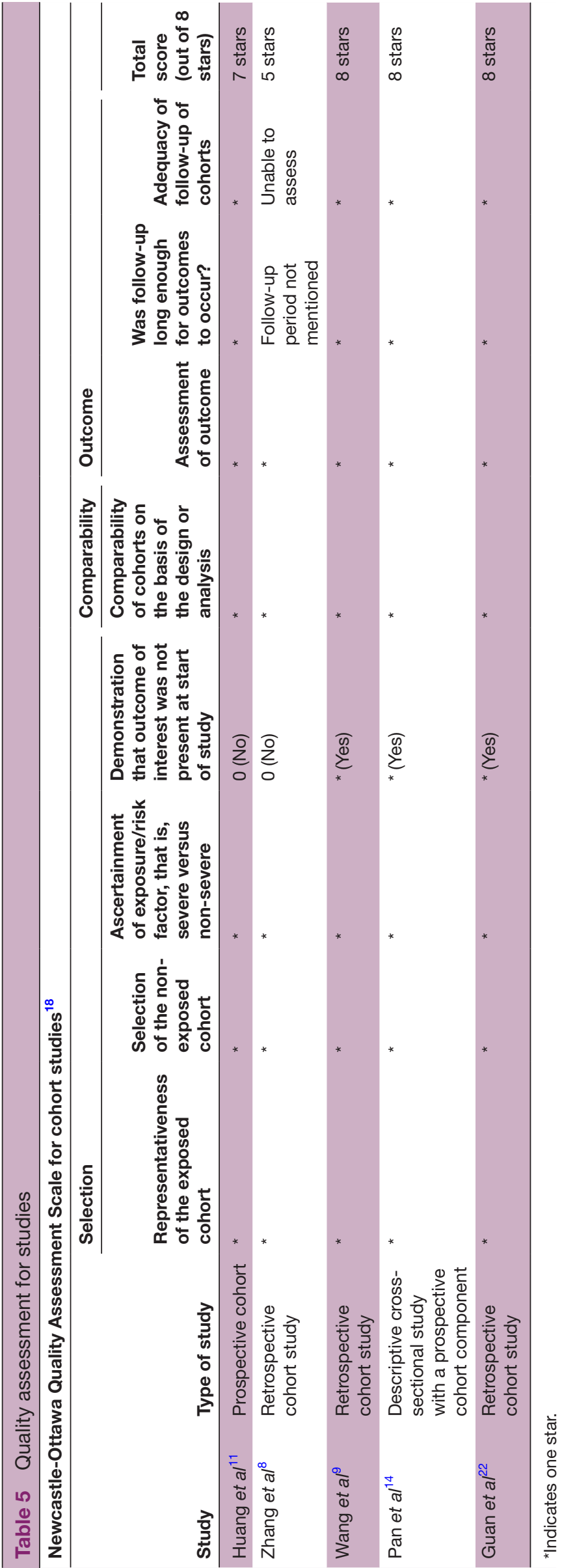

A

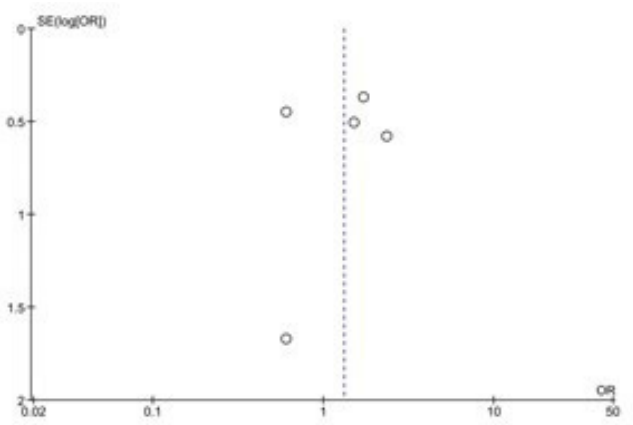

B

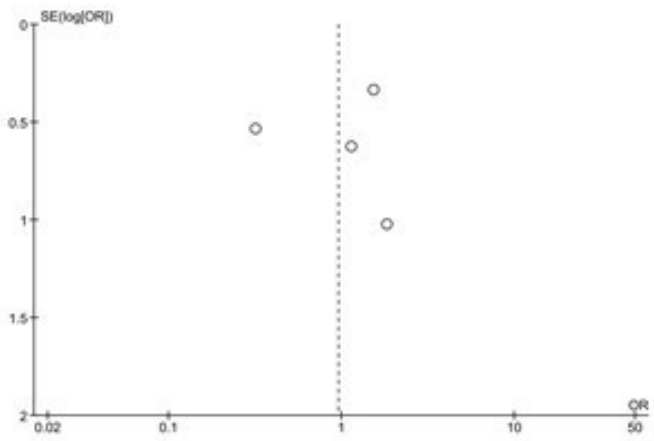

C

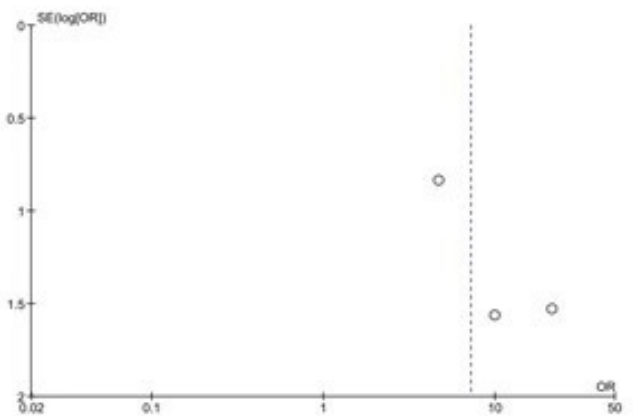

Figure 3 Funnel plots showing publication bias. (A)

Abdominal pain, (B) diarrhoea, (C) nausea and/or vomiting.

Another mechanism of injury involving the GI tract would include the possibility of a systemic inflammatory response to the gut, secondary to viraemia which may lead to an alteration of the gut microbiota. This, in turn, may affect the lung microbiota via the 'gut-lung axis' increasing the risk of developing acute respiratory distress syndrome. ${ }^{142728}$

\section{Strengths and limitations}

To the best of our knowledge, this is one of first GI-specific meta-analysis and largest systematic review that has been conducted regarding COVID-19 comparing severe and non-severe disease. The total analysed sample size was over 2477 patients, allowing for adequate evaluation of the various clinical symptoms. The systematic review also allowed for inferences such as the possibility of a feco-oral transmission of the disease and the possibility of a delay in diagnosis due to GI symptoms being the sole initial presenting complaint of the disease. 
DIARRHOEA

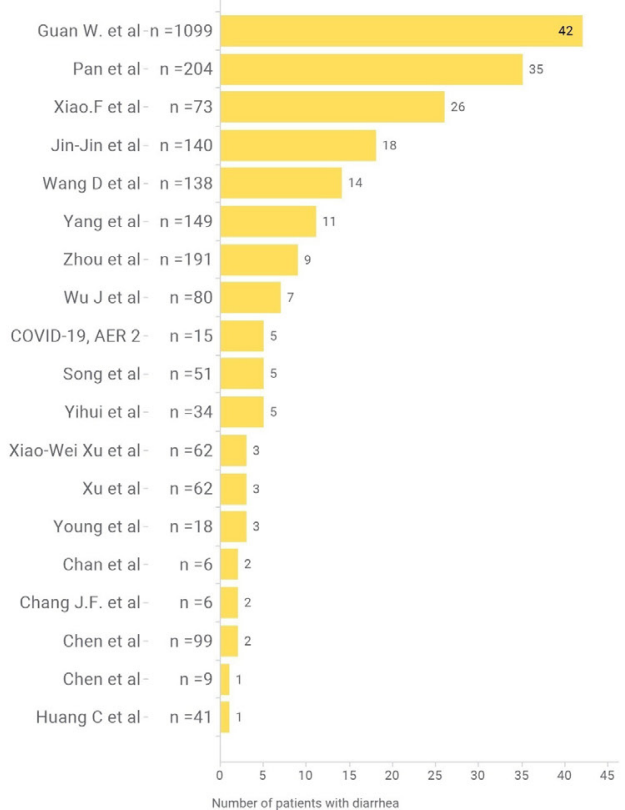

NAUSEA and VOMITING

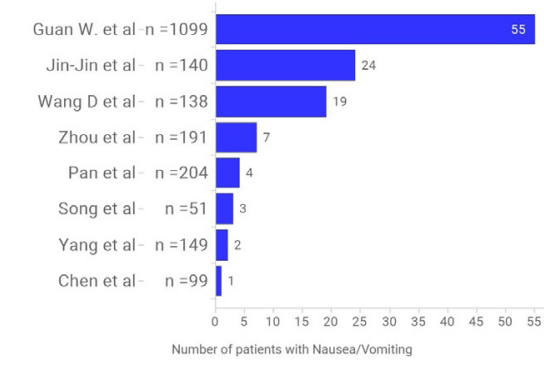

ABDOMINAL PAIN

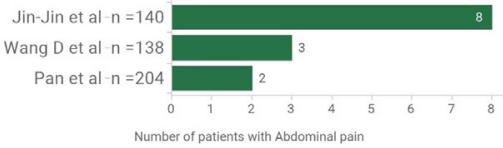

ANOREXIA

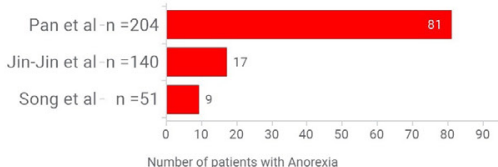

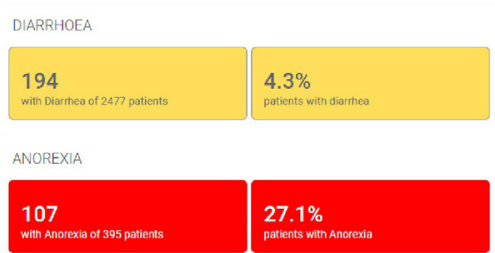

ABDOMINAL PAIN

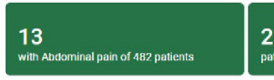

$2.7 \%$

NAUSEA and VOMITING

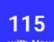

$5.6 \%$

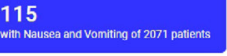

patients with Nausear Vomiting

TLEAST 1 SYMPTOM

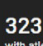

323

$13.0 \%$

Figure 4 Percentage of patients with gastrointestinal symptoms. AER, Australian epidemiological report.

The analysis was not without its own set of limitations. First, the patient samples were geographically isolated to the east and southeast Asian regions, particularly China. Data from elsewhere are lacking. Second, there exists no standardisation on the definition of 'severity' as different studies have implemented different severity grading scales for the same. ${ }^{1920}$ Third, in accordance with other studies, the patient data are limited to those who were hospitalised, creating a selection bias. Fourth, patients had been treated with hydroxychloroquine, lopinavir, and ritonavir, which may have confounded results by virtue of their GI side effects. Fifth, Chinese databases were not included in this study. Lastly, the studies included in the review and analysis were retrospective in nature, introducing a possible bias. ${ }^{29}$

Despite the limitations, the paper seeks to provide valuable insight into the GI manifestations of the COVID-19. It provides evidence that the GI manifestations of the disease sometimes precede the respiratory symptoms, thereby delaying diagnosis. Our findings also reveal that GI symptoms are more common in the severe forms of the disease. This is in concert with some of the data that have been published. ${ }^{14}$ While one may argue that this may be due to the fact that patients with severe disease may possess severe forms of all aspects of the clinical spectrum, it may serve as an important prognostic marker for the overall progression of the disease. Further complicating the matter is the fact that patients with no typical respiratory complaints may delay their presentation to the hospital, thereby delaying the overall diagnosis.

\section{Scope for future research}

As data for COVID-19 continue to grow, so does our understanding of its pathophysiology, mechanism of spread, and clinical features. Future studies exploring a possible feco-oral route of infection via animal models may provide conclusive evidence for the same. At present, very little is known about drugs such as remdesivir, which are undergoing clinical trials. ${ }^{30}$ It is likely that such medications may present with their own possible GI side effects. The studies that have been published at present are largely retrospective in nature, and we anticipate that there will be more prospective studies in the near future. Given that most of the current data are from the inpatient setting, there is a need for studies exploring the disease in the outpatient scenario.

\section{CONCLUSIONS}

GI symptoms are an important clinical finding in patients with COVID-19. Symptoms analysed in this study include diarrhoea, abdominal pain, nausea, and vomiting. Diarrhoea occurs in about $7.8 \%$, and nausea and/or vomiting occurs in $5.5 \%$ of the patients infected. Our meta-analysis using the data from pooled studies indicates that patients with severe disease are seven times more likely to have abdominal pain when compared with patients with nonsevere disease leading to a thought that it might be an indicator of severity.

Acknowledgements We thank our university librarian, Christine Kucharski, for helping us with the literature search.

Contributors VCSK (Conceptualisation: lead; Data curation: equal; Formal analysis: supporting; Methodology: lead; Supervision: equal; Writing-original draft: equal; Writing-review and editing: equal). VCSK is responsible for the overall content of this manuscript. SM (Data curation: equal; Formal analysis: equal; Methodology: equal; Writing-original draft: equal; Writing-review and editing: equal). PH (Data curation: equal; Writing-original draft: equal; Writing-review and editing: equal). AS (Data curation: equal). MKG (Data curation: supporting; Formal analysis: equal; Methodology: supporting). VSP (Formal analysis: lead; Validation: lead; Writing- 
original draft: supporting). BS (Methodology: supporting; Supervision: lead; Writingreview and editing: equal).

Funding The authors have not declared a specific grant for this research from any funding agency in the public, commercial or not-for-profit sectors.

Competing interests None declared.

Patient consent for publication Not required.

Provenance and peer review Not commissioned; externally peer reviewed.

Data availability statement All data relevant to the study are included in the article or uploaded as supplementary information. All relevant data are included in the study.

Open access This is an open access article distributed in accordance with the Creative Commons Attribution Non Commercial (CC BY-NC 4.0) license, which permits others to distribute, remix, adapt, build upon this work non-commercially, and license their derivative works on different terms, provided the original work is properly cited, appropriate credit is given, any changes made indicated, and the use is non-commercial. See: http://creativecommons.org/licenses/by-nc/4.0/.

ORCID iD

Vishnu Charan Suresh Kumar http://orcid.org/0000-0002-9472-2869

\section{REFERENCES}

1 World Health Organization. Coronavirus disease (COVID-19) outbreak. Available: https://www.who.int

2 Chen L, Liu HG, Liu W, et al. [Analysis of clinical features of 29 patients with 2019 novel coronavirus pneumonia]. Zhonghua Jie He He Hu Xi Za Zhi 2020;43:E005.

3 Lu H, Stratton CW, Tang Y-W. Outbreak of pneumonia of unknown etiology in Wuhan, China: the mystery and the miracle. J Med Virol 2020;92:401-2.

4 Paules $\mathrm{Cl}$, Marston HD, Fauci AS. Coronavirus Infections-More than just the common cold. JAMA 2020;323:707-8.

5 Centers for Disease Control and Prevention. Cases in the US Available: https://www.cdc.gov

6 Riou J, Althaus CL. Pattern of early human-to-human transmission of Wuhan 2019 novel coronavirus (2019-nCoV), December 2019 to January 2020. Euro Surveill 2020;25.

7 Chen N, Zhou M, Dong X, et al. Epidemiological and clinical characteristics of 99 cases of 2019 novel coronavirus pneumonia in Wuhan, China: a descriptive study. Lancet 2020;395:507-13.

8 Zhang J-J, Dong X, Cao Y-Y, et al. Clinical characteristics of 140 patients infected with SARS-CoV-2 in Wuhan, China. Allergy 2020 doi:10.1111/all.14238. [Epub ahead of print: 19 Feb 2020].

9 Wang D, Hu B, Hu C, et al. Clinical characteristics of 138 hospitalized patients with 2019 novel coronavirus-infected pneumonia in Wuhan, China. JAMA 2020. doi:10.1001/ jama.2020.1585. [Epub ahead of print: 07 Feb 2020].

10 Yang X, Yu Y, Xu J, et al. Clinical course and outcomes of critically ill patients with SARS-CoV-2 pneumonia in Wuhan, China: a singlecentered, retrospective, observational study. Lancet Respir Med 2020;8:475-81.

11 Huang C, Wang Y, Li X, et al. Clinical features of patients infected with 2019 novel coronavirus in Wuhan, China. Lancet 2020;395:497-506.

$12 \mathrm{Xu} X-\mathrm{W}, \mathrm{Wu} \mathrm{X}-\mathrm{X}$, Jiang X-G, et al. Clinical findings in a group of patients infected with the 2019 novel coronavirus (SARS-
Cov-2) outside of Wuhan, China: retrospective case series. BMJ 2020;368:m606.

13 Borges do Nascimento IJ, Cacic N, Abdulazeem HM, et al. Novel coronavirus infection (COVID-19) in humans: a scoping review and meta-analysis. J Clin Med 2020;9:941.

14 Pan L, Mu M, Yang P, et al. Clinical characteristics of COVID-19 patients with digestive symptoms in Hubei, China: a descriptive, cross-sectional, multicenter study. Am J Gastroenterol 2020;115:766-773.

15 Chan JF-W, Yuan S, Kok K-H, et al. A familial cluster of pneumonia associated with the 2019 novel coronavirus indicating personto-person transmission: a study of a family cluster. Lancet 2020;395:514-23.

16 Xiao F, Tang M, Zheng X, et al. Evidence for gastrointestinal infection of SARS-CoV-2. Gastroenterology 2020;158:1831-3.

17 Harmer D, Gilbert M, Borman R, et al. Quantitative mRNA expression profiling of ACE 2, a novel homologue of angiotensin converting enzyme. FEBS Lett 2002;532:107-10.

18 Wells G, Shea B, O'Connell D, et al. The Newcastle-Ottawa scale (NOS) for assessing the quality of nonrandomised studies in metaanalyses, 2013. Available: http://www.ohri.ca/programs/clinical_ epidemiology/oxford.asp

19 National Chinese Health Commission. Chinese clinical guidance for COVID-19 pneumonia diagnosis and treatment, 7th edition. 抗击新 肺炎. Available: http://kjfy.meetingchina.org/msite/news/show/cn/ 3337.html

20 Metlay JP, Waterer GW, Long AC, et al. Diagnosis and treatment of adults with community-acquired pneumonia. Am J Respir Crit Care Med 2019;200:E45-67.

$21 \mathrm{Hu}$ Z, Song C, Xu C, et al. Clinical characteristics of 24 asymptomatic infections with COVID-19 screened among close contacts in Nanjing, China. Sci China Life Sci 2020;63:706-11.

22 Guan W, Ni Z, Hu Y, et al. Clinical characteristics of coronavirus disease 2019 in China. N Engl J Med 2020.

23 Song F, Shi N, Shan F, et al. Emerging 2019 novel coronavirus (2019nCoV) pneumonia. Radiology 2020;295:210-7.

24 Zhou P, Yang X-L, Wang X-G, et al. A pneumonia outbreak associated with a new coronavirus of probable bat origin. Nature 2020;579:270-3.

25 Munster VJ, Koopmans M, van Doremalen N, et al. A novel coronavirus emerging in China - Key questions for impact assessment. N Engl J Med 2020;382:692-4.

26 Young BE, Ong SWX, Kalimuddin S, et al. Epidemiologic features and clinical course of patients infected with SARS-CoV-2 in Singapore. JAMA 2020. doi:10.1001/jama.2020.3204. [Epub ahead of print: 03 Mar 2020].

27 Budden KF, Gellatly SL, Wood DLA, et al. Emerging pathogenic links between microbiota and the gut-lung axis. Nat Rev Microbiol 2017; 15:55-63.

28 Mukheriee S, Hanidziar D. More of the gut in the lung: how two Microbiomes meet in ARDS. Yale J Biol Med 2018;91:143-9.

29 Norvell DC. Study types and bias-Don't judge a study by the abstract's conclusion alone. Evid Based Spine Care J 2010;1:7-10.

30 Sheahan TP, Sims AC, Leist SR, et al. Comparative therapeutic efficacy of remdesivir and combination lopinavir, ritonavir, and interferon beta against MERS-CoV. Nat Commun 2020;11:222.

31 Huang Y, Tu M, Wang S, et al. Clinical characteristics of laboratory confirmed positive cases of SARS-CoV-2 infection in Wuhan, China: a retrospective single center analysis. Travel Med Infect Dis 2020;27:101606.

$32 \mathrm{Wu} \mathrm{J}, \mathrm{Wu}$ X, Zeng W, et al. Chest CT findings in patients with coronavirus disease 2019 and its relationship with clinical features. Invest Radiol 2020;55:257-61. 